Araştırma Makalesi/Research Article

\title{
Yapay Sinir Ağları Kullanarak Kayısının Farklı Kurutma Yöntemleriyle Kurutulmasında Kuruma Hizı ve Nem Oranı Parametrelerinin Modellenmesi
}

\author{
Ferhat Kurtulmuş* \\ Ahmet Polat iD \\ Nazmi İzli \\ Bursa Uludağ Üniversitesi, Ziraat Fakültesi, Biyosistem Mühendisliği Bölümü, Nilüfer/Bursa, Türkiye \\ *Sorumlu yazar: ferhatk@uludag.edu.tr
}

Geliş Tarihi: 06.05.2020

Kabul Tarihi: 17.09.2020

\section{$\ddot{O} z$}

$\mathrm{Bu}$ çalışmada geleneksel (sıcak hava ile), elektrohidrodinamik (EHD) ve EHD-sıcak hava kombinasyonu kurutma yöntemleriyle kurutulan kayısının farklı kurutma parametrelerinin kuruma hızı ve ürünün nem oranı üzerine etkilerinin YSA ile modellenmesi amaçlanmıştır. Farklı transfer fonksiyonları ve öğrenme algoritmaları denenerek her bir kurutma yöntemi için en iyi model performansını veren YSA tespit edilmiştir. EHD-sıcak hava kombinasyonu ile kayısı kurutmada kuruma hızı ve nem oranı tahminine ilişkin YSA modellerinin test verisi üzerindeki belirtme katsayıları 0,96'dan yüksek değerler olarak saptanmıştır. Araştırma bulguları EHD yöntemi ile tarımsal ürün kurutmanın YSA esaslı yöntemlerle modellenebileceğini göstermiştir.

Anahtar Kelimeler: Kayısı, Kurutma, Modelleme, Yapay sinir ağları

\section{Modeling of Drying Rate and Moisture Ratio Parameters in Drying Apricot with Different Drying Methods Using Artificial Neural Networks \\ Abstract}

In this study, it was aimed to model the effects of different drying parameters of apricot on drying rate and product moisture ratio using $\mathrm{ANN}$ and different drying methods such as traditional (hot air), electrohydradynamic (EHD) and combined EHD-Hot air. The best ANN model performance for each drying method was determined by trying different transfer functions and learning algorithms. The determination coefficients on the test data of the ANN models related to drying rate and moisture ratio estimation in apricot drying with EHD-hot air combination were determined as values higher than 0.96 . The research findings showed that the drying of agricultural crops using EHD could be modeled with ANN-based methods.

Keywords: Apricot, Drying, Modeling, Artificial neural networks

\section{Giriş}

En yaygın olarak yetiştirilen çekirdekli meyvelerden kayısı (Prunus armeniaca L.) Rosaceae ailesine ve Prunaidea alt ailesine aittir (Vega-Gálvez ve ark., 2019). FAO'nun 2018 y1l1 hasat verilerine göre kayısı üretiminin \% 59,3 ‘ü Asya kıtasında gerçekleşirken, Türkiye 750.000 ton ile en yüksek üretim hacmine sahip ülke olarak gösterilmiştir (Anonim, 2020). Kayısı yumuşak dokusu, hoş lezzeti ve yüksek besin değeri ile ön plana çıkan meyvelerden olmuştur. Yapısında bulundurdukları fenolik ve karotenoid bileşikleri ile kardiyovasküler hastalıkların ve bazı kanserlerin oluşmasında azalma sağladığı belirlenmiştir. Kayısılardaki ana karotenoid olan $\beta$-karoten, toplam karotenoidlerin \% 60'ından fazlasını oluşturmakta ve A vitamini öncüsü olarak görme yetisinde önemli bir rol oynamaktadır (Deng ve ark., 2019). Yüksek solunum hızı ve hızlı olgunlaşma süreci nedeniyle çok kısa depolama ömrüne sahip olan kayısı iklimsel ve mevsim meyvesi olarak tanımlanmıştır. Kayısının raf ömrünü uzatmak için, kontrollü atmosferlerde paketleme, dondurma, kurutma ve konserveleme dahil olmak üzere farklı koruma yöntemleri kullanılmıştır (García-Martínez ve ark., 2013). Bu işlemlerin en önemlilerinden biri olan kurutma, meyveler, sebzeler, et, tahıllar ve bitkiler gibi çeşitli gıda maddelerinin raf ömrünü uzatmak ve mevsim dışında kullanılabilir hale getirmek için kullanılan en eski, en ucuz ve en yaygın gıda muhafaza tekniklerinden biri olarak gösterilmiştir (Alwazeer ve Örs, 2019).

Son yıllarda oldukça geniş kullanım alanı bulmuş bir makine öğrenmesi yöntemi olan Yapay sinir ağları (YSA), parametre ve fonksiyon tahmininden sınıflandırmaya kadar çeşitli görevlerde 
karmaşık problemlerin çözümünde kullanılmaktadır. Kısmi veri kümeleri, belirsiz ve yetersiz bilgi içeren görevler için YSA'ların yararlı olduğu bildirilmiştir. Ağlar, proses ilişkileri hakkında önceden bilgi sahibi olmasa bile birden fazla çıktı değişkenini tahmin etmek için farklı girdileri kullanabilme yeteneğine sahiptir (Beigi ve ark., 2017). Birçok makine öğrenmesi yönteminin aksine YSA'nın dayandığ1 temel veriyi oluşturan öznitelikler (değişkenler) arasındaki gizli ilişkileri göz önüne almaktır. YSA'lar önceden gözlemlenebilen veya asıl cevabı bilinen bir parametre dizisi veya sınıflandırma kategorilerini kullanarak öğrenmekte ve buna göre daha önce YSA modelinin görmediği veriyi öğrenme sonucu oluşturulan gizli ağ yapısı ile tahmin edebilmektedir. Bu yaklaşımıyla YSA biyolojik sinir sistemini taklit etmektedir. Nöronlardan oluşan katmanlar YSA'yı oluşturmaktadır. Giriş katmanında eğitim verisindeki öznitelik sayısı kadar nöron bulunur. Hedef çıktı değerleri çıkış katmanında birer nöron ile temsil edilmektedir. Gizli katmanlar ise giriş ve çıkış katmanları arasında yer alır. Nöronlar aktivasyon veya transfer fonksiyonları aracıllğıyla kendilerine ulaşan bilgileri toplayarak bağlı oldukları bir sonraki nöronlara iletirler (Omid ve ark., 2009). Böylelikle bu bilgi akışını sağlayan her bir eğitim iterasyonunda nöron ağırlıkları bir kurala göre güncellenir ve ağ içerisinde bir gizli iliş̧kiler düzeni oluşur.

Kurutmanın karmaşık bir süreç olması nedeniyle çeşitli kurutma koşullarında kuruma hızı ve ürün nem oranını kurutma sürecine göre modelleyen birçok yaklaşım vardır. Yapay sinir ağları bahsedilen avantajları nedeniyle tarımsal ürünlerin kurutulması çalışmalarında da farklı araştırmacılar tarafından kullanılmıştır. Khazaei ve ark. (2013) yaptıkları çalışmada sıcak hava kurutucuda üzüm kurutmasını yapay sinir ağı (YSA) ile modellemişlerdir. Ayrıca Ghaderi ve ark. (2012), Poonnoy ve ark. (2007), Yousefi ve ark. (2013), Krishna Murthy ve Manohar (2012), Motevali ve ark (2013) ve Momenzadeh ve ark. (2011), Chasiotis ve ark. (2019) sirasiyla mantar, domates dilimleri, papaya meyvesi, mango zencefil (Curcuma amada) dereotu yaprakları, misır ve elma ürünlerinin kurutma kinetiklerinin tanımlanması çalışmalarında yapay sinir ağı (YSA) modelleme tekniklerini kullanmışlardır.

Yapılan detaylı literatür taraması kayısının elektrohidrodinamik (EHD) kurutma yöntemleriyle kurutulmasında kuruma hızı ve nem oranı değerlerini tahmin etmede YSA esaslı yöntemlerin kullanımı konularındaki çalışmaların sınırlı olduğunu göstermiştir. Tarım ürünlerinin geleneksel olmayan kurutma yöntemleriyle kurutulması süreçlerinin yapay zeka yöntemleriyle açıklanması önemli bir konudur. Böylelikle ortaya çıkan gelişmiş tahmin modelleriyle geleneksel ve geleneksel olmayan kurutma yöntemlerinin kuruma süresi ve kuruma hızı gibi parametreleri öngörülebilir. Bu çalışmada geleneksel (sıcak hava ile) ve elektrohidradinamik kurutma yöntemi kullanılarak kurutulan kayısının farklı kurutma parametrelerinin kuruma hızı ve ürün nem oranı üzerine etkilerinin Yapay Sinir Ağları ile modellenmesi amaçlanmıştır. Farklı yapay sinir ağı parametreleriyle farklı tahmin modelleri oluşturularak kuruma hızı ve ürün nem oranı için ayrı ayrı YSA modelleri eğitilmiş ve test verisi üzerinde tahmin performansları ortaya konulmuştur.

\section{Materyal ve Yöntem}

Deneylerde kullanılan Hacıhaliloğlu çeşit kayısı örnekleri yerel marketten alınmış ve deneylerin sonuna kadar $4 \pm 0.5^{\circ} \mathrm{C}$ sıcaklık koşullarında tutulmuştur. Örneklerin başlangıçtaki nem içeriği bir etüv (Electromag, Türkiye) kullanılarak kuru bazda (k.b.) 4.81 (g su/g kuru madde) olarak belirlenmiştir.

Zarar görmemiş ve olgun kayısı örnekleri önce ikiye kesilmiş ve daha sonra özel bir küp dilimleyici (Börner, Almanya) ile küp haline getirilmiştir $(7 \times 7 \times 7 \mathrm{~mm})$. Küp haline getirilmiş ürünler ince tabakalar halinde kurutmaya tabi tutulmuştur.

Kurutma işlemi sırasında EHD-tel, EHD-iğne, EHD-tel-sıcak hava, EHD-iğne-sıcak hava ve sıcak hava yöntemleri kullanılmıştır. Deneylerde 2 farklı sıcaklık $\left(40\right.$ ve $\left.50^{\circ} \mathrm{C}\right)$, hava hızı $(1,5$ ve 2,5 $\mathrm{m} / \mathrm{s}$ ) ve voltaj seviyesi (10 ve $20 \mathrm{kV}$ ) belirlenerek EHD, sicak hava ve EHD-sicak hava kombinasyon yöntemleri karşılaştırılmıştır. Kurutma işlemleri, teflon kaplı bir firında gerçekleştirilmiştir. Ürünler paslanmaz çelik bir plaka üzerinde firın içine yerleştirilmiş̧ir. Kurutma için tasarlanan EHD-tel ve EHD-iğne sistemleri ile ürün kritik nem seviyesine gelene kadar kurutulmuştur. EHD-tel sisteminde 6 tel $(0,4 \mathrm{~mm}$ çap) kullanılmış ve aralarındaki mesafe $5 \mathrm{~cm}$, EHD-iğne sisteminde ise 72 iğne $(30 \mathrm{~mm}$ uzunlukta $0.7 \mathrm{~mm}$ çapında) kullanılmış ve iğneler arası mesafe $40 \mathrm{~mm}$ olacak şekilde tasarlanmıştır. 
Ürün ile tel veya iğne elektrodu arasındaki mesafe $30 \mathrm{~mm}$ olarak ayarlanmıştır. Deneyler 3 tekerrürlü olarak gerçekleştirilmiştir.

Bu çalışmada YSA modellerinin oluşturulup test edilmesinde Matlab (2019b) yazılımından yararlanılmıştır. Genel olarak birçok karmaşık problemin çözümü için bir adet gizli katman yeterli olduğundan YSA modelleri oluşturulurken bir giriş katmanı, bir gizli katman ve 1 çıkış katmanından oluşan YSA mimarisi tercih edilmiştir. YSA'lar oluşturulurken gizli katmandaki nöron sayının belirlenmesinde genel olarak kabul edilen kesin bir kural yoktur. Ancak birkaç çalışmada bu sayının belirlenmesiyle ilgili ampirik yöntemler oluşturulmuştur (Heaton, 2015; Priddy ve Keller, 2005). Bu çalışmada YSA mimarileri oluşturulurken kayısı kurutma denemeleri verisi üzerinde ön çalışmalarla farklı nöron sayıları denenmiş ve kuruma hızı ve nem oranı değerlerini tahmin etmede gizli katmanda 5 nöron kullanımının daha fazla sayıda nöron kullanımından daha iyi sonuçlar sağladığı görülmüştür. Böylelikle bu çalışmada oluşturulan tüm YSA mimarilerinde gizli katmandaki nöron sayısı olarak 5 değeri sabit tutulmuştur. Çalışmada kullanılan YSA mimarilerinden birine ait ilustrasyon Şekil 1'de görülmektedir. YSA performansını etkileyen bir diğer unsur transfer fonksiyonlarıdır. Oluşturulan YSA'ların çıktı katmanında lineer transfer fonksiyonu kullanılırken, gizli katmanda tanjant-sigmoid ve logaritmik-sigmoid transfer fonksiyonları ayrı ayrı denenmiştir. $\mathrm{Bu}$ transfer fonksiyonlarına ait eşitlikler aşağıda verilmiştir (Lertworasirikul ve Tipsuwan, 2008):

$$
\begin{aligned}
& \log \operatorname{sig}(x)=\frac{1}{\left(1+e^{-x}\right)} \\
& \tan \operatorname{sig}(x)=\frac{2}{\left(1+e^{-2 x}\right)}-1 \\
& \operatorname{purelin}(x)=x
\end{aligned}
$$

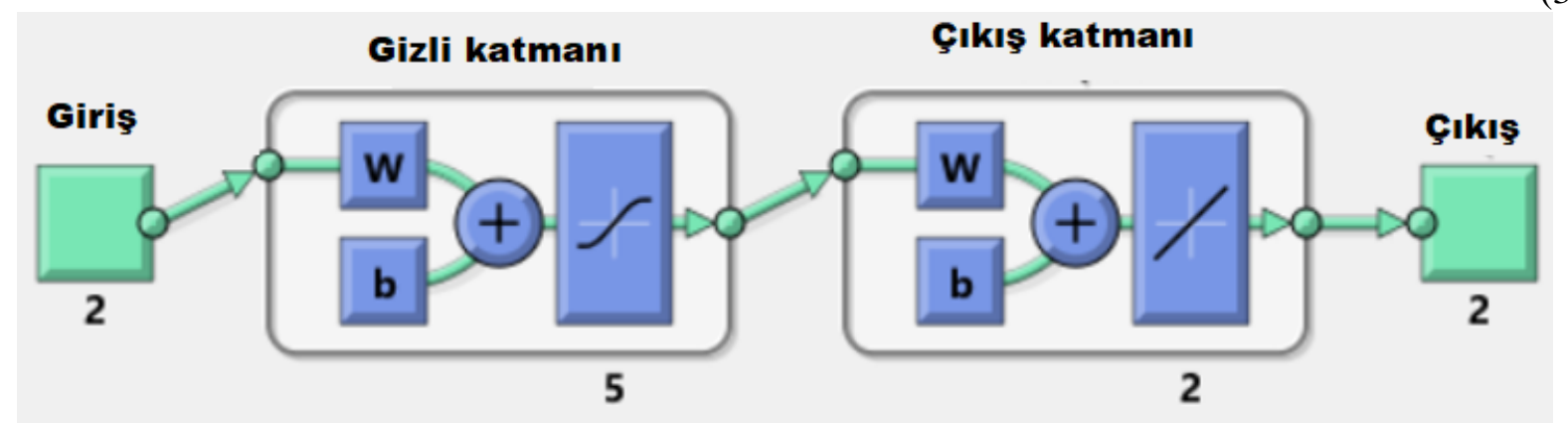

Şekil 1. Çalışmada kullanılan YSA mimarilerinden birine ait ilustrasyon.

YSA'larda nöron ağırlıkları eğitim iterasyonları boyunca belirli bir öğrenme kuralına göre güncellenmektedir. Farklı ögrenme algoritmaları verinin kendine özgü yapısı nedeniyle farklı tahmin performansları ortaya koyabilirler. Bu çalışmada literatürde kullanımına oldukça sık rastlanan dört tanesi yani "Levenberg-Marquardt" (trainlm), "Bayesian regularization backpropagation" (trainbr), "Resilient Backpropagation" (trainrp) ve "Scaled Conjugate Gradient" (trainscg) seçilerek ayrı ayrı denenmiştir (Garoosiha ve ark., 2019). Çalışmada kuruma süresi ve kurutma yöntemi YSA'ya girdi olarak verilirken, ağın nem oranı ve kuruma hızını tahmin etmesi beklenmektedir. Ham deneme verileri yapay sinir ağında kullanılmadan önce MATLAB "mapminmax" fonksiyonu ile normalize edilmiştir. Her YSA denemesinde toplam kurutma denemesi verisinin \%50'si ağın eğitimi için, \%25'i eğitim iterasyonlarındaki doğrulamalar (validasyon) için, kalan \%25'lik veri ise modelin tahmin başarısını ortaya koymak üzere test verisi olarak rasgele seçilerek kullanılmıştır. Gerçek ölçülen değerler ile modelin tahmini arasındaki yakınlık, regresyon için makine öğrenmesi uygulamalarında en çok kullanılan belirtme katsayısı $\left(\mathrm{R}^{2}\right)$ ve hata terimleri (Hata Kareleri Ortalamasının Karekökü (RMSE) ve Ortalama Mutlak Yüzde Hata (MAPE)) ile değerlendirilmiştir (Bankole ve Ajila, 2013; Theocharides ve ark., 2018). Ayrıca MATLAB yazılımının eğitilen ve test edilen YSA'lar için ürettiği eğriler de bulgular kısmında rapor edilmiştir. 


\section{Bulgular ve Tartışma \\ Sıcak hava ile kayısı kurutmanın modellenmesi denemelerine ilişsin YSA modellerinin performansları}

Sıcak hava ile kayısı kurutma verilerinin YSA ile modellenmesi çalışmaları kapsamında 8 adet farklı YSA modeli eğitilerek test verisi üzerinde tahmin performansları gözlemlenmiştir. Tüm verilerden rasgele seçilen \%25'lik test verisi deneysel ve tahmin verileri Çizelge 1'de görülmektedir. Burada görülen tahmin değerleri denenen 8 farklı YSA modelinin en yüksek tahmin başarısını sağlayanına ait değerlerdir. Çizelge 2'de ise sıcak hava ile kayısı kuruma hızının tahminine ilişkin YSA modellerinin performansları verilmiştir. Çizelge 2'de MAPE değerlerinin "Tanımsız" olmasının nedeni test verisinde kuruma hızının sıfır olduğu verilerin de yer almasıdır. Bu deneme grubunda en yüksek $\mathrm{R}^{2}$ değerinin öğrenme algoritması olarak trainlm ve gizli katman transfer fonksiyonunun tanjant-sigmoid olduğu YSA modelinde elde edildiği görülmektedir. Ayrıca bu modelin RMSE hata değeri de $(0,009512)$ oldukça düşüktür. Çizelgeler 1 ve 2 genel olarak değerlendirildiğinde sıcak hava ile kayısı kurutmanın YSA ile modellenmesinde yüksek bir tahmin başarısı sağlandığı söylenebilir.

Çizelge 1. Sıcak hava ile kayısı kurutma test verisi deneysel ve tahmin değerleri (En yüksek başarı için)

\begin{tabular}{llcccc}
\hline & & $\begin{array}{c}\text { Kuruma hiz1 } \\
\text { (g su/g kuru } \\
\text { madde.dak) }\end{array}$ & Nem oranı & $\begin{array}{c}\text { Kuruma hiz1 } \\
\text { (g su/g kuru } \\
\text { madde.dak) }\end{array}$ & Nem oranı \\
\hline Süre (dakika) & Yöntem & \multicolumn{2}{c}{ Deneysel değerler } & Tahmin değerleri \\
\hline 60 & $40^{\circ} \mathrm{C}-1,5 \mathrm{~m} / \mathrm{s}$ & 0,11 & 0,81 & 0,11 & 0,76 \\
90 & $40^{\circ} \mathrm{C}-1,5 \mathrm{~m} / \mathrm{s}$ & 0,10 & 0,71 & 0,10 & 0,68 \\
210 & $40^{\circ} \mathrm{C}-1,5 \mathrm{~m} / \mathrm{s}$ & 0,05 & 0,45 & 0,05 & 0,46 \\
300 & $40^{\circ} \mathrm{C}-1,5 \mathrm{~m} / \mathrm{s}$ & 0,04 & 0,30 & 0,03 & 0,31 \\
450 & $40^{\circ} \mathrm{C}-1,5 \mathrm{~m} / \mathrm{s}$ & 0,02 & 0,15 & 0,02 & 0,14 \\
540 & $40^{\circ} \mathrm{C}-1,5 \mathrm{~m} / \mathrm{s}$ & 0,01 & 0,11 & 0,01 & 0,10 \\
630 & $40^{\circ} \mathrm{C}-1,5 \mathrm{~m} / \mathrm{s}$ & 0,01 & 0,09 & 0,01 & 0,08 \\
720 & $40^{\circ} \mathrm{C}-1,5 \mathrm{~m} / \mathrm{s}$ & 0,01 & 0,07 & 0,01 & 0,06 \\
330 & $40^{\circ} \mathrm{C}-2,5 \mathrm{~m} / \mathrm{s}$ & 0,03 & 0,15 & 0,03 & 0,17 \\
390 & $40^{\circ} \mathrm{C}-2,5 \mathrm{~m} / \mathrm{s}$ & 0,02 & 0,11 & 0,02 & 0,12 \\
480 & $40^{\circ} \mathrm{C}-2,5 \mathrm{~m} / \mathrm{s}$ & 0,01 & 0,07 & 0,02 & 0,07 \\
570 & $40^{\circ} \mathrm{C}-2,5 \mathrm{~m} / \mathrm{s}$ & 0,01 & 0,04 & 0,01 & 0,04 \\
630 & $40^{\circ} \mathrm{C}-2,5 \mathrm{~m} / \mathrm{s}$ & 0,00 & 0,04 & 0,01 & 0,03 \\
690 & $40^{\circ} \mathrm{C}-2,5 \mathrm{~m} / \mathrm{s}$ & 0,00 & 0,03 & 0,00 & 0,03 \\
750 & $40^{\circ} \mathrm{C}-2,5 \mathrm{~m} / \mathrm{s}$ & 0,00 & 0,03 & 0,00 & 0,02 \\
30 & $50^{\circ} \mathrm{C}-1,5 \mathrm{~m} / \mathrm{s}$ & 0,13 & 0,87 & 0,13 & 0,83 \\
90 & $50^{\circ} \mathrm{C}-1,5 \mathrm{~m} / \mathrm{s}$ & 0,13 & 0,55 & 0,14 & 0,55 \\
210 & $50^{\circ} \mathrm{C}-1,5 \mathrm{~m} / \mathrm{s}$ & 0,07 & 0,22 & 0,06 & 0,21 \\
360 & $50^{\circ} \mathrm{C}-1,5 \mathrm{~m} / \mathrm{s}$ & 0,01 & 0,03 & 0,03 & 0,01 \\
150 & $50^{\circ} \mathrm{C}-2,5 \mathrm{~m} / \mathrm{s}$ & 0,10 & 0,29 & 0,09 & 0,27 \\
210 & $50^{\circ} \mathrm{C}-2,5 \mathrm{~m} / \mathrm{s}$ & 0,08 & 0,12 & 0,06 & 0,12 \\
300 & $50^{\circ} \mathrm{C}-2,5 \mathrm{~m} / \mathrm{s}$ & 0,01 & 0,03 & 0,03 & 0.00 \\
\hline
\end{tabular}

Çizelge 3'te sıcak hava ile kayısı kurumada nem tahminine ilişkin YSA modellerinin performansları verilmiştir. Kuruma hızında en yüksek tahmin performansını sağlayan YSA modelinin nem tahmininde de en yüksek $\mathrm{R}^{2}$ değerini (0,997221) sağladığı görülmektedir. Mükemmel tahmin başarısına oldukça yakın olan bu performans için RMSE değerinin oldukça düşük ve MAPE değerinin de \%20'den az olduğu böylelikle modelin iyi tahmin sınıfinda olduğu sonucuna varılmıştır (Moreno ve ark., 2013). 
Çizelge 2. Sıcak hava ile kayısı kuruma hızının tahminine ilişkin YSA modellerinin performansları

\begin{tabular}{lcccccc}
\hline $\begin{array}{c}\text { Öğrenme } \\
\text { algoritmas1 }\end{array}$ & $\mathrm{R}^{2}$ & RMSE & MAPE & $\mathrm{R}^{2}$ & RMSE & MAPE \\
\hline & \multicolumn{4}{c}{$\begin{array}{c}\text { Gizli katman transfer } \\
\text { fonksiyonu: } \\
\text { Tanjant-sigmoid }\end{array}$} & \multicolumn{3}{c}{$\begin{array}{c}\text { Gizli katman transfer } \\
\text { fonksiyonu: } \\
\text { Logaritmik-sigmoid }\end{array}$} \\
\hline trainlm & $\mathbf{0 , 9 5 5 7 3 7}$ & $\mathbf{0 , 0 0 9 5 1 2}$ & Tanımsız & 0,951504 & 0,010002 & Tanıms1z \\
trainscg & 0,553612 & 0,029714 & Tanımsiz & 0,529431 & 0,030421 & Tanımsız \\
trainbr & 0,942577 & 0,011198 & Tanımsız & 0,950513 & 0,010343 & Tanımsız \\
trainrp & 0,642364 & 0,028417 & Tanımsız & 0,781432 & 0,02389 & Tanımsız \\
\hline
\end{tabular}

Çizelge 3. Sıcak hava ile kayısı kurumada nem tahminine ilişkin YSA modellerinin performansları

\begin{tabular}{|c|c|c|c|c|c|c|}
\hline $\begin{array}{l}\text { Öğrenme } \\
\text { algoritmas1 }\end{array}$ & $\mathrm{R}^{2}$ & RMSE & MAPE & $\mathrm{R}^{2}$ & RMSE & MAPE \\
\hline & \multicolumn{3}{|c|}{$\begin{array}{l}\text { Gizli katman transfer } \\
\text { fonksiyonu: } \\
\text { Tanjant-sigmoid } \\
\end{array}$} & \multicolumn{3}{|c|}{$\begin{array}{l}\text { Gizli katman transfer } \\
\text { fonksiyonu: } \\
\text { Logaritmik-sigmoid } \\
\end{array}$} \\
\hline train & 97221 & 0,019314 & 0,1364 & 0,997095 & & 0,1026 \\
\hline trainscg & 9841 & 0,0334 & 0,367722 & 0,925868 & 0,073664 & 0,80 \\
\hline trainbr & 0,993828 & 0,0208 & 0,232 & 0,993538 & 0,021498 & 0,209401 \\
\hline trainrp & 0,929359 & 0,072174 & 0,619435 & 0,951373 & 0,058453 & 0,479171 \\
\hline
\end{tabular}

YSA modelleri eğitilirken aşırı öğrenme (over-fitting) durumunun gerçekleşip gerçekleşmediğinin mutlaka kontrolünün yapılması gereklidir. Eğitim boyunca tutulan eğitim ve doğrulama setlerine ait hata kaydı gözlenerek bu kontrol gerçekleştirilebilir. Doğrulama ve test hata eğrilerinin eğitim iterasyonları boyunca birbirlerinden zıt yönlerde bir seyir izlemesi, istenmeyen bir durumdur ve YSA eğitiminin istenilen seviyede başarılamadığı anlamına gelmektedir. Şekil 2'de bu deneme grubunda en başarılı sonucu veren YSA eğitimine ait hata kayıt grafiği verilmiştir. YSA eğitimi 12. eğitim iterasyonunda tamamlanmıştır. Grafikte yeşil halka ile gösterilen bu iterasyonda, en düşük doğrulama hatası elde edilmiştir. YSA modelinin bu iterasyondaki hali kayıt edilerek test verisi üzerindeki performans denemeleri için kullanılmıştır. Grafikte doğrulama ve test hata vektörlerinin benzer bir seyir izlediği görülmektedir. Böylelikle bu YSA modelinin eğitimi sırasında aşırı öğrenme durumunun gerçekleşmediği sonucuna varılmıştır.

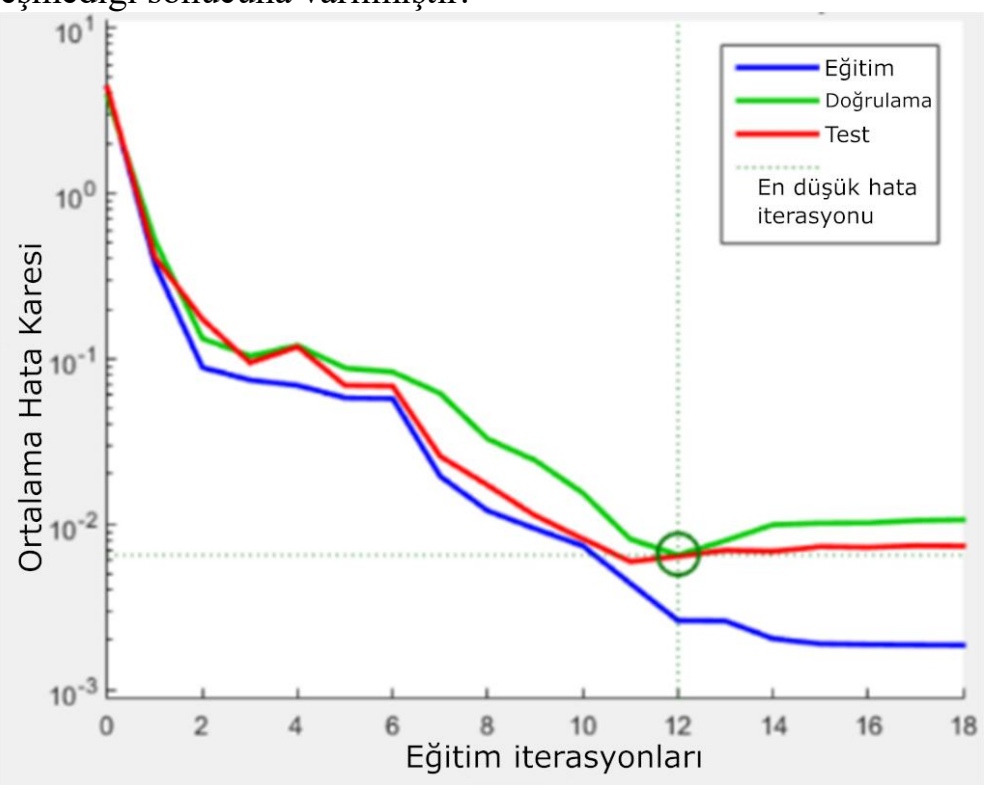

Şekil 2. Sıcak hava ile kayısı kuruma modellemesinde en yüksek tahmin performansını sağlayan YSA modeli eğitim hata kayd. 


\section{EHD ile kayısı kurutmanın modellenmesi denemelerine ilişkin YSA modellerinin performansları}

EHD ile kayısı kurutma verisinin YSA ile modellenmesi çalışmaları kapsamında 8 adet farklı YSA modeli eğitilerek test verisi üzerinde tahmin performansları gözlemlenmiştir. Çizelge 4 'de en yüksek tahmin başarısını sağlayan YSA modeli için \%25'lik test verisi üzerinde deneysel ve tahmin değerleri verilmiştir. Çizelge 5'te bu deneme grubunda kuruma hızının tahminine yönelik denenen YSA modellerine ilişkin performans parametreleri görülmektedir. Değerler incelendiğinde tüm modeller için başarının yüksek olmadığı, ancak trainbr öğrenme algoritması ve logaritmik-sigmoid transfer fonksiyonu için kuruma hızı tahmininde belirtme katsayısı değerinin 0,876244 olarak elde edildiği görülmektedir. Ayrıca MAPE değerleri bu deneme grubunda bütün modeller için $\% 20$ ile \%50 arasında bulunmuştur. Moreno ve ark. (2013)'e göre bu deneme grubunda en yüksek belirtme katsayısına sahip model "makul tahmin" sınıfindadır. Daha yüksek tahminleme başarılarının bu deneme grubunda elde edilememesi, kullanılabilir eğitim verisinin görece azlığı ile açıklanabilir.

Çizelge 4. EHD ile kayısı kurutma test verisi deneysel ve tahmin değerleri (En yüksek başarı için)

\begin{tabular}{llcccc}
\hline & & \multicolumn{2}{c}{$\begin{array}{l}\text { Kuruma hızı } \\
\text { (g su/g kuru } \\
\text { madde.dak) }\end{array}$} & Nem oranı & \multicolumn{2}{l}{$\begin{array}{l}\text { Kuruma hızı } \\
\text { (g su/g kuru } \\
\text { madde.dak) }\end{array}$} & Nem oranı \\
\hline Süre & Yöntem & \multicolumn{2}{c}{ Deneysel değerler } & \multicolumn{2}{c}{ Tahmin değerleri } \\
\hline 240 & $20 \mathrm{kV}$-iğne & 0,17 & 0,61 & 0,09 & 0,67 \\
360 & $20 \mathrm{kV}$-iğne & 0,14 & 0,46 & 0,08 & 0,58 \\
840 & $20 \mathrm{kV}$-iğne & 0,05 & 0,19 & 0,05 & 0,22 \\
1200 & $20 \mathrm{kV}$-iğne & 0,03 & 0,08 & 0,03 & 0,06 \\
120 & $20 \mathrm{kV}$-tel & 0,23 & 0,76 & 0,11 & 0,68 \\
480 & $20 \mathrm{kV}$-tel & 0,09 & 0,31 & 0,08 & 0,40 \\
\hline
\end{tabular}

Çizelge 5. EHD ile kayısı kuruma hızının tahminine ilişkin YSA modellerinin performansları

\begin{tabular}{lcccccc}
\hline $\begin{array}{c}\text { Öğrenme } \\
\text { algoritmas1 }\end{array}$ & $\mathrm{R}^{2}$ & RMSE & MAPE & $\mathrm{R}^{2}$ & RMSE & MAPE \\
\hline & \multicolumn{3}{c}{$\begin{array}{c}\text { Gizli katman transfer } \\
\text { fonksiyonu: } \\
\text { Tanjant-sigmoid }\end{array}$} & \multicolumn{3}{c}{$\begin{array}{c}\text { Gizli katman transfer } \\
\text { fonksiyonu: } \\
\text { Logaritmik-sigmoid }\end{array}$} \\
\hline trainlm & 0,298884 & 0,061475 & 30,14022 & 0,340643 & 0,059693 & 22,28111 \\
trainscg & 0,370371 & 0,076923 & 43,83395 & 0,498052 & 0,070886 & 36,44385 \\
trainbr & 0,593297 & 0,058196 & 26,41011 & $\mathbf{0 , 8 7 6 2 4 4}$ & $\mathbf{0 , 0 6 5 2 2}$ & $\mathbf{2 8 , 2 7 6 2 7}$ \\
trainrp & 0,747636 & 0,06233 & 45,69943 & 0,263581 & 0,073433 & 40,75007 \\
\hline
\end{tabular}

Çizelge 6. EHD ile kayısı kurumada nem tahminine ilişkin YSA modellerinin performansları

\begin{tabular}{lcccccc}
\hline $\begin{array}{c}\text { Öğrenme } \\
\text { algoritmas1 }\end{array}$ & $\mathrm{R}^{2}$ & RMSE & MAPE & $\mathrm{R}^{2}$ & RMSE & MAPE \\
\hline & \multicolumn{3}{c}{$\begin{array}{c}\text { Gizli katman transfer } \\
\text { fonksiyonu: } \\
\text { Tanjant-sigmoid }\end{array}$} & \multicolumn{3}{c}{$\begin{array}{c}\text { Gizli katman transfer } \\
\text { fonksiyonu: } \\
\text { Logaritmik-sigmoid }\end{array}$} \\
\hline trainlm & 0,996632 & 0,022618 & 11,34098 & 0,997862 & 0,011306 & 2,853145 \\
trainscg & 0,599413 & 0,150083 & 31,0211 & 0,628379 & 0,156068 & 52,73392 \\
trainbr & $\mathbf{0 , 9 9 8 0 9 9}$ & $\mathbf{0 , 0 1 1 2 8 3}$ & $\mathbf{2 , 5 2 9 5 8 3}$ & 0,922125 & 0,074238 & 19,87036 \\
trainrp & 0,526515 & 0,248528 & 79,41896 & 0,965706 & 0,045211 & 20,55025 \\
\hline
\end{tabular}

Çizelge 6'da EHD ile kayısı kurumada nem oranı tahminine ilişkin YSA modellerinin performansları verilmiştir. Nem oranı değeri trainlm öğrenme algoritması ile 0,99 değerinin üzerinde performanslar ile saptanabildiği görülmektedir. Tanjant-sigmoid fonksiyonu ile trainbr öğrenme 
algoritmasının kullanıldığı tahmin modelinin en yüksek başarıyı sağladığı saptanmıştır. Bu modelin belirtme katsayısı 1'e oldukça yakındır. RMSE $(0,011)$ ve MAPE $(\% 2,53)$ hata terimleri de oldukça düşük olarak bulunmuştur. Ayrıca trainlm öğrenme algoritmasıyla oluşturulan tahmin modelleriyle de yüksek belirtme katsayıları elde edilmesine ragmen bu modeller için hata terimleri (RMSE ve MAPE) daha yüksektir.

EHD-sıcak hava kombinasyonu ile kayısı kurutmanın modellenmesi denemelerine ilişkin YSA modellerinin performansları

EHD-sıcak hava kombinasyonu ile kayısı kurutma verisinin YSA ile modellenmesi çalışmaları kapsamında 8 adet farklı YSA modeli eğitilerek test verisi üzerinde tahmin performansları gözlemlenmiştir. Çizelge 7'de test verisi deneysel ve tahmin değerleri görülmektedir. Bu deneme grubunda en yüksek tahmin başarısını $(0,964924)$ sağlayan YSA modeli trainbr/tanjant-sigmoid modeli olmuştur (Çizelge 8). RMSE hata değeri de oldukça düşük olarak hesaplanmıştır. Bu model MAPE değerine göre de $(\% 10<\mathrm{MAPE}<\% 20)$ iyi tahmin modeli kategorisindedir (Moreno ve ark., 2013). Diğer YSA modellerinin çoğu da yüksek seviyelerde tahmin başarısı ortaya koymuştur. Kuruma hızının bu deneme grubunda başarıyla tahmin edilebildiği söylenebilir.

Çizelge 7. EHD-sıcak hava kombinasyonu ile kayısı kurutma test verisi deneysel ve tahmin değerleri (En yüksek başarı için)

\begin{tabular}{llcccc}
\hline & & $\begin{array}{l}\text { Kuruma hizı } \\
\text { (g su/g kuru } \\
\text { madde.dak) }\end{array}$ & Nem oran1 & $\begin{array}{l}\text { Kuruma hiz1 } \\
\text { (g su/g kuru } \\
\text { madde.dak) }\end{array}$ & Nem oranı \\
\hline Süre(dakika) & Yöntem & \multicolumn{2}{c}{ Deneysel değerler } & \multicolumn{2}{c}{ Tahmin değerleri } \\
\hline 60 & $10 \mathrm{kV}-40^{\circ} \mathrm{C}$-iğne & 0,17 & 0,52 & 0,16 & 0,53 \\
90 & $10 \mathrm{kV}-40^{\circ} \mathrm{C}$-iğne & 0,12 & 0,40 & 0,11 & 0,41 \\
210 & $10 \mathrm{kV}-40^{\circ} \mathrm{C}$-iğne & 0,05 & 0,14 & 0,04 & 0,14 \\
300 & $10 \mathrm{kV}-40^{\circ} \mathrm{C}$-iğne & 0,02 & 0,04 & 0,02 & 0,04 \\
90 & $20 \mathrm{kV}-40^{\circ} \mathrm{C}$-iğne & 0,13 & 0,31 & 0,12 & 0,31 \\
150 & $20 \mathrm{kV}-40^{\circ} \mathrm{C}$-iğne & 0,07 & 0,14 & 0,06 & 0,15 \\
180 & $20 \mathrm{kV}-40^{\circ} \mathrm{C}$-iğne & 0,04 & 0,09 & 0,04 & 0,10 \\
270 & $20 \mathrm{kV}-40^{\circ} \mathrm{C}$-iğne & 0,01 & 0,03 & 0,02 & 0,02 \\
60 & $10 \mathrm{kV}-50^{\circ} \mathrm{C}$-iğne & 0,19 & 0,38 & 0,22 & 0,38 \\
\hline
\end{tabular}

Çizelge 8. EHD-sıcak hava kombinasyonu ile kayısı kuruma hızının tahminine ilişkin YSA modellerinin performansları

\begin{tabular}{|c|c|c|c|c|c|c|}
\hline $\begin{array}{l}\text { Öğrenme } \\
\text { algoritmas1 }\end{array}$ & $\mathrm{R}^{2}$ & RMSE & MAPE & $\mathrm{R}^{2}$ & RMSE & MAPE \\
\hline & \multicolumn{3}{|c|}{$\begin{array}{l}\text { Gizli katman transfer } \\
\text { fonksiyonu: } \\
\text { Tanjant-sigmoid } \\
\end{array}$} & \multicolumn{3}{|c|}{$\begin{array}{l}\text { Gizli katman transfer } \\
\text { fonksiyonu: } \\
\text { Logaritmik-sigmoid }\end{array}$} \\
\hline trainlm & 0,92377 & 0,02515 & 34,14746 & 0,929627 & 0,020743 & 17,11374 \\
\hline trainscg & 0,894651 & 0,07104 & 58,59634 & 0,679992 & 0,038708 & 81,50836 \\
\hline trainbr & 0,964924 & 0,012315 & 17,54127 & 0,955569 & 0,01331 & 14,11235 \\
\hline trainrp & 0,8845 & 0,093541 & 85,15249 & 0,926066 & 0,07663 & 77,77767 \\
\hline
\end{tabular}

Çizelge 9'da EHD-sıcak hava kombinasyonu ile kayısı kurutmada nem oranı tahminine ilişkin YSA modellerinin performansları görülmektedir. EHD-sıcak hava kombinasyonu için en yüksek nem oranı tahmin başarısı $(0,998291)$ benzer şekilde trainbr/tanjant -sigmoid modeli ile elde edilmiştir. Diğer modeller de 0,90 değerinin üzerinde tahmin başarıları göstermiştir. Bu tahmin modeli için RMSE ve MAPE değerleri sırasıyla yaklaşık 0,008 ve \%8,58 olarak bulunmuştur. Bu deneme grubu için YSA yöntemi kullanarak ile yüksek bir tahmin başarısı elde edildiği söylenebilir. 
Çizelge 9. EHD-sıcak hava kombinasyonu ile kayısı kurutmada nem tahminine ilişkin YSA modellerinin performanslar1

\begin{tabular}{lccccccc}
\hline $\begin{array}{c}\text { Öğrenme } \\
\text { algoritmas1 }\end{array}$ & $\mathrm{R}^{2}$ & RMSE & MAPE & $\mathrm{R}^{2}$ & RMSE & MAPE \\
\hline & \multicolumn{3}{c}{$\begin{array}{c}\text { Gizli katman transfer } \\
\text { fonksiyonu: } \\
\text { Tanjant-sigmoid }\end{array}$} & \multicolumn{3}{c}{$\begin{array}{c}\text { Gizli katman transfer } \\
\text { fonksiyonu: } \\
\text { Logaritmik-sigmoid }\end{array}$} \\
\hline trainlm & 0,990727 & 0,01731 & 7,935636 & 0,931223 & 0,050652 & 32,17279 \\
trainscg & 0,969739 & 0,042242 & 23,92444 & 0,92214 & 0,126967 & 37,28596 \\
trainbr & $\mathbf{0 , 9 9 8 2 9 1}$ & $\mathbf{0 , 0 0 8 4 1 3}$ & $\mathbf{8 , 5 8 2 5 4 8}$ & 0,991591 & 0,01645 & 8,826872 \\
trainrp & 0,982378 & 0,068009 & 43,11986 & 0,965683 & 0,031373 & 30,89697 \\
\hline
\end{tabular}

Literatürde kayısının elektrohidrodinamik yöntemlerle kurutulması ve bu süreçlerin YSA ile modellenmesine yönelik sınırlı sayıda çalışma olması, araştırma bulgularının birebir adil bir karşılaştırma ile yorumlanmasını güçleştirmektedir. Ancak, yine de tartışılmaya değer bazı bulgulara değinmekte yarar vardır. Khazaei ve ark. (2013) sıcak hava ile üzüm kurutma denemelerinde ürün nem oranının YSA ile test verisi üzerinde yüksek bir doğruluk $\left(\mathrm{R}^{2}=0,99952\right)$ ile modelleyebilmişlerdir. Motevali ve ark. (2013) benzer şekilde dereotu kurutulmasında YSA esaslı modelleme çalışmasını gerçekleştirmişlerdir. Araştırmacılar kuruma oranı ve ürün nemi tahmininde determinasyon katsayısını 0,9990 olarak bildirmişlerdir. Ayva dilimlerinin kurutulmasının YSA ile modellenmesine yönelik gerçekleştirilen diğer bir çalışmada ise determinasyon katsayısı 0,99 olarak bildirilmiştir (Chasiotis ve ark., 2019). Kayısının farklı yöntemlerle kurutulduğu bu çalışmada literatürde bildirilen tahmin performanslarına benzer başarı değerleri elde edilmiştir. Bu durum, tarım ürünlerinin kurutulma süreçlerinin YSA esaslı olarak modellenebilmesi potansiyelini desteklemektedir.

\section{Sonuç}

$\mathrm{Bu}$ çalışmada kayısının geleneksel olmayan elektrohidrodinamik kurutma yöntemiyle kurutulmasında kuruma hızı ve nem parametrelerinin YSA ile modellenmesi yapılmıştır. Ürün farklı voltaj seviyeleri $(10$ ve $20 \mathrm{kV})$, sicaklık $\left(40\right.$ ve $\left.50{ }^{\circ} \mathrm{C}\right)$ ve hava hizı $(1,5$ ve $2,5 \mathrm{~m} / \mathrm{s})$ kullanılan EHDtel, EHD-iğne ve EHD-sıcak hava kombinasyon yöntemleri ile kurutularak YSA modellemesi için gerekli veri elde edilmiştir. Farklı öğrenme algoritmaları ve transfer fonksiyonları kullanarak oluşturulan YSA modelleri eğitim verisi ile eğitilerek test verisi üzerinde tahmin performansları ortaya konulmuştur. Sicak hava ile kurutma denemelerinde kuruma hızı ve nem oranı değerlerinin tahmini için en yüksek model başarıları sırasıyla 0,9557 ve 0,9972 olarak elde edilmiştir. EHD yöntemi ile ise kuruma hızı ve nem için en yüksek tahmin başarıları sırasıyla 0,8762 ve 0,9979 'dur. EHD-sıcak hava kombinasyonu ile kayısı kurutmada kuruma hızı ve nem tahminine ilişkin YSA modellerinin performansları da 0,96'dan yüksek değerler olarak saptanmıştır. Araştırma bulguları EHD yöntemi ile tarımsal ürün kurutmanın YSA esaslı yöntemlerle modellenebilmesi bakımından umut vericidir. Gelecek çalışmalarda farklı ürünlerin geleneksel olmayan yöntemlerle kurutulmasında farklı makine öğrenmesi yöntemlerinin modelleme performanslarının ortaya konulması önerilmektedir.

\section{Teşekkür}

Bu çalışmayı 1170793 nolu proje kapsamında destekleyen Türkiye Bilimsel ve Teknolojik Araştırma Kurumu (TÜBİTAK)'a teşekkür ederiz.

\section{Kaynaklar}

Alwazeer, D., Örs, B., 2019. Reducing atmosphere drying as a novel drying technique for preserving the sensorial and nutritional notes of foods. J. Food Sci. Technol., 56(8): 3790-3800.

Anonim, 2020 FAO (Food and Agriculture Organization of the United Nations) http://www.fao.org/faostat/en/\#data/QC/visualize. Erişim Tarihi: 09.04.2020.

Bankole, A.A. Ajila, S.A., 2013. Predicting cloud resource provisioning using machine learning techniques. In: 2013 26th IEEE Canadian Conference on Electrical and Computer Engineering (CCECE), 1-4.

Beigi, M., Torki-Harchegani, M., Tohidi, M., 2017. Experimental and ANN modeling investigations of energy traits for rough rice drying. Energy, 141: 2196-2205. 
Chasiotis, V.K., Tzempelikos, D.A., Filios, A.E., Moustris, K.P., 2019. Artificial neural network modelling of moisture content evolution for convective drying of cylindrical quince slices. Comput. Electron. Agr., 105074.

Deng, L.Z., Pan, Z., Mujumdar, A.S., Zhao, J.H., Zheng, Z.A., Gao, Z.J., Xiao, H.W., 2019. High-Humidity hot air impingement blanching (HHAIB) enhances drying quality of apricots by inactivating the enzymes, reducing drying time and altering cellular structure. Food Control, 96: 104-111.

García-Martínez, E., Igual, M., Martín-Esparza, M.E., Martínez-Navarrete, N., 2013. Assessment of the bioactive compounds, color, and mechanical properties of apricots as affected by drying treatment. Food Bioprocess Tech., 6(11): 3247-3255.

Garoosiha, H., Ahmadi, J., Bayat, H., 2019. The Assessment of levenberg-marquardt and bayesian framework training algorithm for prediction of concrete shrinkage by the artificial neural network. Cogent Eng., 6(1): 1609179.

Ghaderi, A., Abbasi, S., Motevali, A., Minaei, S., 2012. Comparison of mathematical models and artificial neural networks for prediction of drying kinetics of mushroom in microwave-vacuum drier. Chem. Ind. Chem. Eng. Q., 18(2): 283-293.

Heaton, J., 2015. Introduction to Neural Networks for Java: Feedforward Backpropagation Neural Networks. http://www.heatonresearch.com/node/707. Erişim Tarihi: 04.12.2016.

Khazaei, N.B., Tavakoli, T., Ghassemian, H., Khoshtaghaza, M.H., Banakar, A., 2013. Applied machine vision and artificial neural network for modeling and controlling of the grape drying process. Comput. Electron. Agr., 98: 205-213.

Krishna Murthy, T.P., Manohar, B., 2012. Microwave drying of Mango Ginger (Curcuma Amada Roxb): prediction of drying kinetics by mathematical modelling and artificial neural network. International J. Food Sci. Technol., 47(6): 1229-1236.

Lertworasirikul, S., Tipsuwan, Y., 2008. Moisture content and water activity prediction of semi-finished cassava crackers from drying process with artificial neural network. J. Food Eng., 84(1): 65-74.

Momenzadeh, L., Zomorodian, A., Mowla, D., 2011. Experimental and theoretical investigation of shelled corn drying in a microwave-assisted fluidized bed dryer using artificial neural network. Food Bioprod Process., 89(1): 15-21.

Moreno, J.J.M., Pol, A.P., Abad, A.S. Blasco, B.C., 2013. Using the R-MAPE index as a resistant measure of forecast accuracy. Psicothema, 25(4): p:500-506.

Motevali, A., Younji, S., Chayjan, R.A., Aghilinategh, N., Banakar, A., 2013. Drying kinetics of dill leaves in a convective dryer. Int Agrophys., 27(1): 39.

Omid, M., Mahmoudi, A., Omid, M.H., 2009. An Intelligent System for Sorting Pistachio Nut Varieties. Expert Syst. App., 36(9): 11528-11535.

Poonnoy, P., Tansakul, A., Chinnan, M., 2007. Artificial neural network modeling for temperature and moisture content prediction in tomato slices undergoing microwave-vacuum drying. J. Food Sci., 72(1): E042E047.

Priddy, K.L., Keller, P.E., 2005. Artificial Neural Networks: An Introduction (SPIE Tutorial Texts in Optical Engineering), The International Society for Optical Engineering, Bellingham, Washington, USA.

Theocharides, S., Makrides, G., Georghiou, G.E., Kyprianou, A., 2018. Machine learning algorithms for photovoltaic system power output prediction. In: 2018 IEEE International Energy Conference (ENERGYCON), 1-6.

Vega-Gálvez, A., Quispe-Fuentes, I., Uribe, E., Martinez-Monzo, J., Pasten, A., Lemus-Mondaca, R., 2019. Bioactive compounds and physicochemical characterization of dried Apricot (Prunus Armeniaca L.) as affected by different drying temperatures. CYTA-J. Food., 17(1): 297-306.

Yousefi, A., Asadi, V., Nassiri, S.M., Niakousari, M., Aghdam, S.K., 2013. Comparison of mathematical and neural network models in the estimation of papaya fruit moisture content. Philipp. Agric. Sci., 95(3): 192-198. 